\section{(C) OPEN ACCESS}

\title{
Cardiovascular risk after hospitalisation for unexplained syncope and orthostatic hypotension
}

\author{
Ekrem Yasa, ${ }^{1,2}$ Fabrizio Ricci, ${ }^{3,4}$ Martin Magnusson, ${ }^{1,2}$ Richard Sutton, ${ }^{5}$ Sabina Gallina, ${ }^{3}$ \\ Raffaele De Caterina, ${ }^{3}$ Olle Melander, ${ }_{1}^{1}$ Artur Fedorowski ${ }^{1,2}$
}

\begin{abstract}
${ }^{1}$ Department of Clinical Sciences, Lund University, Clinical Research Center, Skåne University Hospital, Malmö, Sweden

${ }^{2}$ Department of Cardiology, Skåne University Hospital, Malmö, Sweden

${ }^{3}$ Institute of Cardiology, University 'G. d'Annunzio', Chieti, Italy

${ }^{4}$ Department of Neuroscience and Imaging and ITAB Institute Advanced Biomedical Technologies, University 'G. d'Annunzio', Chieti, Italy ${ }^{5}$ National Heart and Lung Institute, Imperial College, Hammersmith Hospital Campus, London, UK
\end{abstract}

\section{Correspondence to} Dr Artur Fedorowski, Department of Cardiology, Inga Marie Nilssons gata 46, Skåne University Hospital, 205 02 Malmö, Sweden; artur. fedorowski@med.lu.se

Received 14 May 2017 Revised 25 June 2017 Accepted 4 July 2017 Published Online First 8 August 2017

\section{SLinked}

- http://dx.doi.org/10.1136/ heartjnl-2017-312112

Check for updates

To cite: Yasa $E$, Ricci $F$ Magnusson $\mathrm{M}$, et al. Heart 2018;104:487-493.

\section{ABSTRACT}

Objective To investigate the relationship of hospital admissions due to unexplained syncope and orthostatic hypotension $(\mathrm{OH})$ with subsequent cardiovascular events and mortality.

Methods We analysed a population-based prospective cohort of 30528 middle-aged individuals (age $58 \pm 8$ years; males, 40\%). Adjusted Cox regression models were applied to assess the impact of unexplained syncope/OH hospitalisations on cardiovascular events and mortality, excluding subjects with prevalent cardiovascular disease.

Results After a median follow-up of $15 \pm 4$ years, 524 (1.7\%) and 504 (1.7\%) participants were hospitalised for syncope or $\mathrm{OH}$, respectively, yielding 1.2 hospital admissions per 1000 person-years for each diagnosis. Syncope hospitalisations increased with age (HR, per 1 year: $1.07,95 \% \mathrm{Cl} 1.05$ to 1.09), higher systolic blood pressure (HR, per $10 \mathrm{~mm} \mathrm{Hg:} 1.06,95 \% \mathrm{Cl} 1.01$ to 1.12 ), antihypertensive treatment (HR: $1.26,95 \% \mathrm{Cl}$ 1.00 to 1.59 ), use of diuretics (HR: $1.77,95 \% \mathrm{Cl} 1.31$ to 2.38 ) and prevalent cardiovascular disease (HR: 1.59, $95 \% \mathrm{Cl} 1.14$ to 2.23 ), whereas $\mathrm{OH}$ hospitalisations increased with age (HR: $1.11,95 \% \mathrm{Cl} 1.08$ to 1.12$)$ and prevalent diabetes (HR: $1.82,95 \% \mathrm{Cl} 1.23$ to 2.70 ). After exclusion of 1399 patients with prevalent cardiovascular disease, a total of 473/464 patients were hospitalised for unexplained syncope/OH before any cardiovascular event. Hospitalisation for unexplained syncope predicted coronary events (HR: $1.85,95 \% \mathrm{Cl} 1.49$ to 2.30 ), heart failure (HR: $2.24,95 \% \mathrm{Cl} 1.65$ to 3.04), atrial fibrillation (HR: $1.84,95 \% \mathrm{Cl} 1.50$ to 2.26 ), aortic valve stenosis (HR: $2.06,95 \% \mathrm{Cl} 1.28$ to 3.32 ), all-cause mortality (HR: $1.22,95 \% \mathrm{Cl} 1.09$ to 1.37$)$ and cardiovascular death (HR: $1.72,95 \% \mathrm{Cl} 1.23$ to 2.42). OH-hospitalisation predicted stroke (HR: $1.66,95 \% \mathrm{Cl} 1.24$ to 2.23 ), heart failure (HR: $1.78,95 \% \mathrm{Cl} 1.21$ to 2.62 ), atrial fibrillation (HR: $1.89,95 \% \mathrm{Cl} 1.48$ to 2.41 ) and all-cause mortality (HR: $1.14,95 \% \mathrm{Cl} 1.01$ to 1.30 ).

Conclusions Patients discharged with the diagnosis of unexplained syncope or $\mathrm{OH}$ show higher incidence of cardiovascular disease and mortality with only partial overlap between these two conditions.

\section{INTRODUCTION}

Syncope and orthostatic hypotension $(\mathrm{OH})$ are frequently diagnosed in patients admitted to hospital due to transient loss of consciousness (T-LOC), and both have been associated with worse prognosis in population-based studies. ${ }^{12}$
The diagnosis of syncope (R55.9, International Classification of Diseases (ICD)-10) is often referred to as a synonym for reflex syncope, the most common cause of T-LOC, accounting for about $50 \%-60 \%$ of cases. Conversely, $\mathrm{OH}$ is believed to coexist with $10 \%-15 \%$ of T-LOC episodes, ${ }^{3}$ which are then defined as syncope due to $\mathrm{OH}$ or autonomic failure. It is universally accepted that recurrent reflex syncope and $\mathrm{OH}$ are different clinical manifestations of cardiovascular (CV) autonomic dysfunction. Reflex syncope is an intermittent condition with varying frequency; patients are asymptomatic and appear normal between attacks that may recur only after years. ${ }^{3}$ In contrast, $\mathrm{OH}$ is a chronic underlying dysfunction of the autonomic nervous system, varying symptomatology and occasional syncope. ${ }^{4}$ Although $\mathrm{OH}$ and reflex syncope may overlap, especially when orthostatic blood pressure (BP) fall induces a vasovagal reflex, characteristically in delayed $\mathrm{OH},{ }^{3}$ these two conditions are seen as separate entities. Unfortunately, the ICD system does not offer a specific 'reflex syncope' code complicating discrimination of syncope aetiologies.

Population-based studies exploring incidence and consequences of hospitalisations where the final diagnosis was unexplained but most likely reflex syncope, ${ }^{35}$ or more definitely $\mathrm{OH}$, are very sparse. In consequence, discharged patients and their doctors may feel uncertain whether this index incident may imply future risk of CV disease. Moreover, $\mathrm{OH}$ is typically a demonstration of abnormal orthostatic BP response, ${ }^{4}$ rather than syncope precipitating hospital admission with its prospective risks being based on screening data, including large numbers of asymptomatic subjects.

In this study, we assessed the occurrence of hospitalisations with a final discharge diagnosis of unexplained syncope or $\mathrm{OH}$ in a large population-based middle-aged cohort. We then explored the prognostic relationship of these hospitalisations to CV morbidity/mortality among study participants without prevalent CV disease at hospital discharge.

\section{METHODS \\ Study cohort}

The Malmö Diet and Cancer Study is a prospective cohort study in which all men born between 1923 and 1945 and women born between 1923 and 1950 from the city of Malmö, Sweden (total population: 330 000), were invited to participate. The participation rate was $\sim 40 \%$. Men and women, 


\begin{tabular}{|c|c|c|c|}
\hline \multicolumn{4}{|c|}{$\begin{array}{l}\text { Cancer Study } \\
\text { nean age: } 58 \pm 8 \text { years) } \\
6 \text { - Follow-up: } 15 \pm 4 \text { years } \\
\text { 504; unexplained syncope, } n=528 \\
378 \text {; dead } n=6866 \text {; emigrated } n=284\end{array}$} \\
\hline \multicolumn{4}{|c|}{$\begin{array}{l}\text { Exclusion of prevalent CV disease }(n=1399) \\
29,129 \text { subjects eligible for further analysis }\end{array}$} \\
\hline Outcomes & $\begin{array}{c}\text { OH hospital } \\
\text { admission } \\
(n=464)\end{array}$ & $\begin{array}{l}\text { Syncope hospital } \\
\text { admission } \\
(n=473)\end{array}$ & $\begin{array}{c}\text { No hospital } \\
\text { admission } \\
(n=28,192)\end{array}$ \\
\hline Coronary event & 86 & 101 & 2241 \\
\hline Heart failure & 49 & 52 & 829 \\
\hline Atrial fibrillation & 125 & 124 & 2348 \\
\hline Stroke & 91 & 70 & 1901 \\
\hline Aortic stenosis & 17 & 24 & 374 \\
\hline CV death & 47 & 52 & 1594 \\
\hline All-cause death & 121 & 138 & 5230 \\
\hline
\end{tabular}

Figure 1 Flow chart summarising the selection process of study population. CV, cardiovascular; $\mathrm{OH}$, orthostatic hypotension.

total of 30,528, underwent a baseline examination 1991-1996. ${ }^{6}$ The average follow-up has been $15 \pm 4$ years (figure 1). Full description of recruitment and screening procedures have been provided elsewhere. $^{7}$

\section{Definition of clinical characteristics}

The participants underwent measurement of body weight and height and BP and filled a questionnaire on health, lifestyle and socioeconomic factors and medications. BP was measured using a mercury-column sphygmomanometer and properly sized right arm cuff after $10 \mathrm{~min}$ rest in supine position. Hypertension was defined, according to current guidelines, as systolic BP $\geq 140 \mathrm{~mm} \mathrm{Hg}$ and/ or diastolic BP $\geq 90 \mathrm{~mm} \mathrm{Hg}$, or use of antihypertensive medications. $^{8} \mathrm{OH}$ was assessed by the method subsequently published by a consensus group in 2011. ${ }^{9}$ Baseline diabetes was defined as self-reported physician diagnosis of diabetes or use of antidiabetic medications. Baseline questionnaire recorded the smoking status. The study complied with the Declaration of Helsinki, and the protocol was approved by the regional ethics committee.

\section{Ascertainment of clinical endpoints}

All study participants were followed-up through 31 December 2011 by linking a unique 10-digit personal identification number with Swedish National Hospital Discharge Register (SNHDR), Swedish National Cause of Death Register (SNCDR) and Stroke Register of Malmö (STROMA). Event-free subjects $(n=284 ; 0.9 \%)$ emigrating from Sweden before 31 December 2011 were assigned date of emigration as last follow-up date. We examined two primary outcomes: (1) first-time hospital admission for unexplained syncope or $\mathrm{OH}$; and (2) first-ever $\mathrm{CV}$ event defined as coronary event, stroke, atrial fibrillation, heart failure and aortic valve stenosis. We also analysed two secondary outcomes: CV death and all-cause mortality. Data on the first-time hospitalisation for unexplained syncope or $\mathrm{OH}$ were based on primary or main secondary discharge diagnoses according to the ICD-9/10 system (syncope: ICD-9=780.2, and ICD-10=R550.9; OH: ICD-9=458 and ICD-10=I951) as retrieved from SNHDR, excluding cases with concurrent $\mathrm{CV}$ diagnoses identified as the primary cause of admission, such as acute coronary syndrome (myocardial infarction or unstable angina), stroke or transient ischaemic attack, cardiac arrhythmia, acute decompensated heart failure and valvular heart disease. In the case that the hospital admission was recorded for both unexplained syncope and $\mathrm{OH}$, we classified the event as $\mathrm{OH}$ related, as in-hospital $\mathrm{OH}$ diagnosis warrants a positive orthostatic test.

Coronary event was defined as fatal or non-fatal myocardial infarction or death due to coronary heart disease on basis of ICD-9 and ICD-10 codes 410 and I21, respectively, in SNHDR and codes 410, 412 and 414 (ICD-9) or I21-I23 and I25 (ICD$10)$ in SNCDR. The register-based diagnosis of coronary event in SNHDR has been found to be highly valid. ${ }^{10}$

Fatal or non-fatal stroke was defined according to ICD9 and ICD10 as cases coded 430, 431, 434 and 436 or I60, I61, I63 and I64, respectively. STROMA was used for case retrieval. In addition, SNHDR and SNCDR were used for retrieval of patients who moved out of Malmö. As in previous studies, the outcome of atrial fibrillation was defined as either a diagnosis of atrial fibrillation or atrial flutter and ascertained using diagnosis codes 427.92 for ICD-8, 427D for ICD-9 and I48 for ICD-10. Heart failure (HF) was defined using codes 429 for ICD-9 and I50 and I11.0 for ICD-10. The primary diagnosis of HF in SNHDR has been shown to have an accuracy of $95 \% .{ }^{11}$ Aortic valve stenosis was defined using codes 424.1 for ICD-9 and I35.0 for ICD-10, including both discharge and surgical diagnoses. In subjects with more than one specific CV event, only the first event was used for analysis.

\section{Statistical analysis}

Group differences in continuous variables were compared using Student's t-test. Dichotomous variables were compared using Pearson's $\chi^{2}$ test. Clinical determinants of syncope and OH-related hospital admissions were analysed using a multivariable-adjusted Cox regression model, controlling for conventional risk factors.

After exclusion of all cases that were preceded by prevalent $\mathrm{CV}$ disease at baseline, we further assessed the risk for incident $\mathrm{CV}$ events associated with syncope or $\mathrm{OH}$-related hospitalisations. Recorded outcomes were first related to different covariates in an unadjusted model. Thereafter, a Cox proportional hazards analysis was used to calculate adjusted HRs for the coronary event, stroke, heart failure, new-onset atrial fibrillation and aortic valve stenosis associated with prior admission for unexplained syncope or $\mathrm{OH}$. Age, sex, systolic blood pressure, use of antihypertensive therapy, current smoking, diabetes, body mass index (BMI) and use of hypolipidaemic agents were forced to enter the final model. We fitted two different Cox models, each including antihypertensive treatment or different classes of antihypertensive medications, with all other covariates remaining stable. We used the same analytical approach to evaluate potential predictors of first-time hospital admission for unexplained syncope or $\mathrm{OH}$, here including also prevalent $\mathrm{CV}$ disease and cancer prior to the assessed event.

Thereafter, cumulative probabilities of all-cause and CV death stratified according to presence or absence of incident hospital admission for unexplained syncope or $\mathrm{OH}$ in the participant's history were calculated using the Kaplan-Meier method, and quantified using the log-rank test. Thereafter, Cox proportional hazards analysis was applied to calculate adjusted HR for both all-cause and $\mathrm{CV}$ death associated with hospital admissions for $\mathrm{OH}$ or syncope.

Two baseline variables had missing values: BMI and systolic BP (SBP). These were always $<0.2 \%$ of the sample $(n<60)$ and were 
Table 1 Baseline characteristics of study population stratified by incident hospital admission for OH or unexplained syncope during follow-up

\begin{tabular}{|c|c|c|c|c|}
\hline Characteristic & $\begin{array}{l}\text { No } \mathrm{OH} / \text { syncope } \\
\text { hospitalisation } n=29500\end{array}$ & OH hospitalisation $n=504$ & $\begin{array}{l}\text { Unexplained syncope } \\
\text { hospitalisation } n=524\end{array}$ & $p$ Value \\
\hline Age (years) & $57 \pm 8$ & $63 \pm 7$ & $62 \pm 7$ & $<0.001$ \\
\hline Sex (male, \%) & 37.5 & 47.4 & 50.0 & $<0.001$ \\
\hline Body mass index $\left(\mathrm{kg} / \mathrm{m}^{2}\right)$ & $26 \pm 4$ & $26 \pm 4$ & $27 \pm 4$ & $<0.001$ \\
\hline Systolic BP (mm Hg) & $141 \pm 20$ & $147 \pm 21$ & $148 \pm 21$ & $<0.001$ \\
\hline Diastolic BP (mm Hg) & $86 \pm 10$ & $87 \pm 10$ & $88 \pm 10$ & $<0.001$ \\
\hline Hypertension (\%) & 61.0 & 70.6 & 74.4 & $<0.001$ \\
\hline AHT (\%) & 17.1 & 24.8 & 27.7 & $<0.001$ \\
\hline Diabetes (\%) & 3.4 & 7.4 & 5.6 & $<0.001$ \\
\hline Current smoking (\%) & 28.4 & 24.6 & 25.1 & 0.053 \\
\hline Prevalent CVD (\%) & 4.4 & 7.9 & 9.7 & $<0.001$ \\
\hline Prevalent cancer (\%) & 6.2 & 6.9 & 5.2 & 0.48 \\
\hline
\end{tabular}

$\mathrm{AHT}$, antihypertensive treatment; $\mathrm{BP}$, blood pressure; $\mathrm{CVD}$, cardiovascular disease; $\mathrm{OH}$, orthostatic hypotension.

replaced by the average of remaining determinations. There were no missing values in any outcome. All tests were two sided; $\mathrm{p}<0.05$ was considered statistically significant. All calculations were performed using SPSS statistical software V.23 for Mac and GraphPad Prism V.6.0 for Mac (GraphPad Software, La Jolla, California, USA).

\section{RESULTS}

The mean age of study population was $58 \pm 8$ years; $40 \%$ were men; $61 \%(n=18706)$ had hypertension at baseline (table 1$)$. A total of 1028 patients $(3.4 \%)$ had at least one hospitalisation for either unexplained syncope $(n=524,1.71 \%)$ or $\mathrm{OH}(\mathrm{n}=504,1.65 \%)$.

The average time between baseline and first admission for syncope/OH was $12.3 \pm 4.5$ years, and the mean age at first hospitalisation was $74.4 \pm 7.6$ years (range, $50-88$ years).

Patients hospitalised for syncope/OH were older, more often male, had higher BMI and higher proportions of hypertension, diabetes and history of CV disease (table 1).

Hospitalisations for syncope were predicted by higher SBP, antihypertensive treatment, in particular use of diuretics, and baseline $\mathrm{CV}$ disease, whereas $\mathrm{OH}$-related hospital admissions were predicted by history of diabetes, but not by antihypertensive treatment (table 2).

During follow-up, first-ever coronary event occurred in 2851, stroke in 2307 , new-onset heart failure in 1207 , atrial fibrillation in 2824 and aortic valve stenosis in 489 persons. Prevalence of $\mathrm{CV}$ disease at baseline plus prior to first incident hospitalisation for unexplained syncope/OH was 4.6\% $(n=1399)$, yielding 29129 participants eligible for further analyses. Nine hundred and thirty-seven patients were hospitalised due to unexplained syncope $(n=473)$ or $\mathrm{OH}(n=464)$ prior to any CV event, that is, first $\mathrm{CV}$ event or diagnosis was recorded at least 7 days after hospital discharge. The average time between first admission for syncope/OH and first-ever CV event was $3.6 \pm 3.5$ years.

In Kaplan-Meier survival analysis, both incidence of coronary events and stroke were significantly higher among patients who had been hospitalised for $\mathrm{OH}$ or unexplained syncope. Patients with syncope-related hospital admission showed a near-significant trend (log-rank test, $\mathrm{p}=0.061$ ) towards higher rate of coronary events compared with those having incident $\mathrm{OH}$-related admissions (figure 2A). In contrast, $\mathrm{OH}$-related hospitalisation was associated with significantly higher incident risk of stroke (log-rank test, $\mathrm{p}=0.017$ ) (figure $2 \mathrm{~B}$ ). Multivariable-adjusted Cox regression analyses showed history of syncope hospitalisation was associated with higher risk of incident coronary events, heart failure, atrial fibrillation and aortic valve stenosis, while history of $\mathrm{OH}$ hospitalisation predicted incident stroke, heart failure and atrial fibrillation (figure 3).

Table 2 Multivariable-adjusted analysis evaluating potential predictors of recorded outcomes

\begin{tabular}{|c|c|c|c|c|}
\hline \multirow[b]{2}{*}{ Covariate at baseline } & \multicolumn{2}{|c|}{ OH hospitalisation $n=504$} & \multicolumn{2}{|c|}{ Unexplained syncope hospitalisation $n=524$} \\
\hline & $\begin{array}{l}\text { Adjusted HR } \\
(95 \% \mathrm{Cl})\end{array}$ & $p$ Value & $\begin{array}{l}\text { Adjusted HR } \\
(95 \% \mathrm{Cl})\end{array}$ & $p$ Value \\
\hline Female gender & $0.82(0.67$ to 1.01$)$ & 0.061 & 0.81 (0.66 to 0.98$)$ & 0.033 \\
\hline Mean BMI, 1-unit increase & $0.97(0.94$ to 1.00$)$ & 0.025 & $1.03(1.00$ to 1.05$)$ & 0.033 \\
\hline Mean age, 1 year increase & 1.11 (1.08 to 1.12$)$ & $<0.001$ & 1.07 (1.05 to 1.09$)$ & $<0.001$ \\
\hline Current cigarette smoking & $0.99(0.77$ to 1.26$)$ & 0.93 & 1.10 (0.87 to 1.38$)$ & 0.426 \\
\hline Diabetes & $1.82(1.23$ to 2.70$)$ & 0.003 & 1.20 (0.79 to 1.84$)$ & 0.386 \\
\hline Prevalent CVD & $1.30(0.89$ to 1.89$)$ & 0.183 & 1.59 (1.14 to 2.23$)$ & 0.007 \\
\hline Prevalent cancer & $0.73(0.48$ to 1.11$)$ & 0.147 & $0.75(0.50$ to 1.13$)$ & 0.167 \\
\hline Systolic BP, $10 \mathrm{~mm} \mathrm{Hg}$ increase & $1.05(0.99$ to 1.10$)$ & 0.099 & $1.06(1.01$ to 1.12$)$ & 0.024 \\
\hline ACE-inhibitor & $1.06(0.65$ to 1.73$)$ & 0.828 & 0.80 (0.49 to 1.31$)$ & 0.378 \\
\hline Beta-blocker & $1.17(0.87$ to 1.58$)$ & 0.293 & $0.92(0.69$ to 1.23$)$ & 0.584 \\
\hline Calcium channel blocker & 0.74 (0.48 to 1.14$)$ & 0.177 & $1.10(0.77$ to 1.57$)$ & 0.589 \\
\hline Diuretic & $1.06(0.74$ to 1.53$)$ & 0.741 & 1.77 (1.31 to 2.38$)$ & $<0.001$ \\
\hline $\mathrm{AHT}^{*}$ & 1.14 (0.89 to 1.46$)$ & 0.304 & $1.26(1.00$ to 1.59$)$ & 0.050 \\
\hline
\end{tabular}

*Excluding the four classes of antihypertensive drugs from the model.

$\mathrm{AHT}$, antihypertensive treatment; $\mathrm{BMI}$, body mass index; $\mathrm{BP}$, blood pressure; $\mathrm{CVD}$, cardiovascular disease; $\mathrm{OH}$, orthostatic hypotension. 


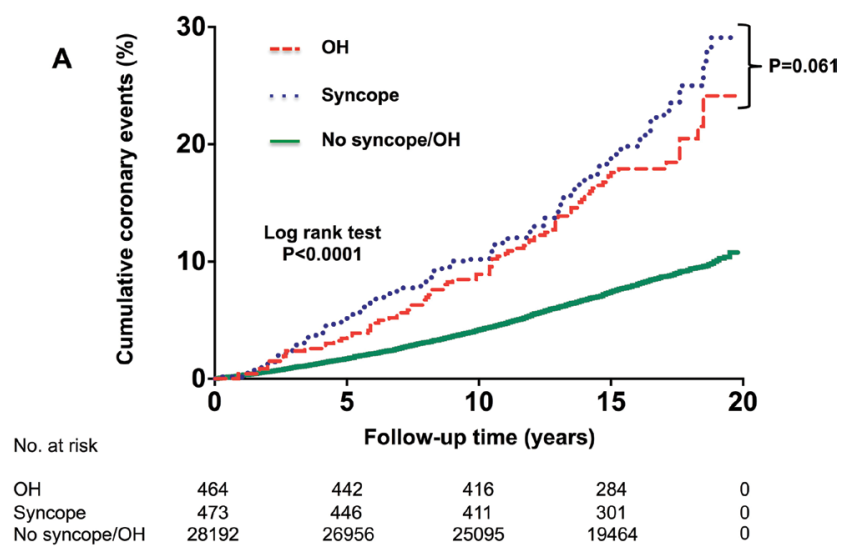

B

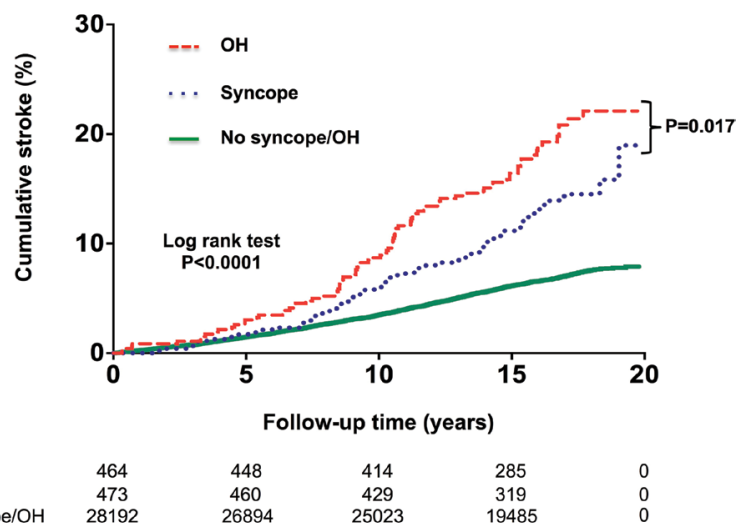

Figure 2 Long-term cumulative incidence of coronary events and stroke according to incident unexplained syncope- and orthostatic hypotension (OH)-related hospital admission ( $n=29129)$. Kaplan-Meier curves with regard to coronary events (A) and stroke (B) stratified according to incident syncope-related (blue) and $\mathrm{OH}$-related (red) hospital admissions: in both cases showing significantly lower eventfree survival rate (Log-rank test: $p<0.001)$ compared with patients never hospitalised for syncope or $\mathrm{OH}$ (green). Patients with a firstever incident syncope-related hospital admission showed a nearsignificant trend (Log-rank test: $p=0.061$ ) towards higher coronary event rate compared with incident $\mathrm{OH}$-related admission. $\mathrm{OH}$-related hospitalisation was associated with a significantly higher risk of stroke (Log-rank test: $\mathrm{p}=0.017$ ).

Six thousand and eight hundred sixty-six patients (22.5\%) died and 354 deaths were preceded by hospitalisation for unexplained syncope/OH. In Kaplan-Meier survival analysis, CV and all-cause mortality rates were significantly higher among patients who had been hospitalised for unexplained syncope $(p<0.001)$ compared with individuals never being hospitalised for syncope/ $\mathrm{OH}$ (figure 4). In multivariable-adjusted Cox proportional hazard model, adjusting for conventional risk factors, history of syncope hospitalisation was an independent predictor of both CV mortality (adjusted HR: $1.72,95 \%$ CI 1.23 to $2.42, \mathrm{p}=0.002$ ) and all-cause mortality (adjusted HR: 1.22 , 95\% CI 1.09 to $1.37, \mathrm{p}=0.001$ ), whereas $\mathrm{OH}$-related hospital admission independently predicted all-cause mortality (adjusted HR: 1.14, 95\% CI 1.01 to 1.30 , $\mathrm{p}=0.032)$ with a trend towards significance for CV mortality (adjusted HR: 1.33, 95\% CI 0.93 to 1.92, $\mathrm{p}=0.124$ ) (table 3).

\section{DISCUSSION}

Our study reports that hospital admissions for syncope and $\mathrm{OH}$ in middle-aged adults increase with age and convey independent prognostic information with important differences between the

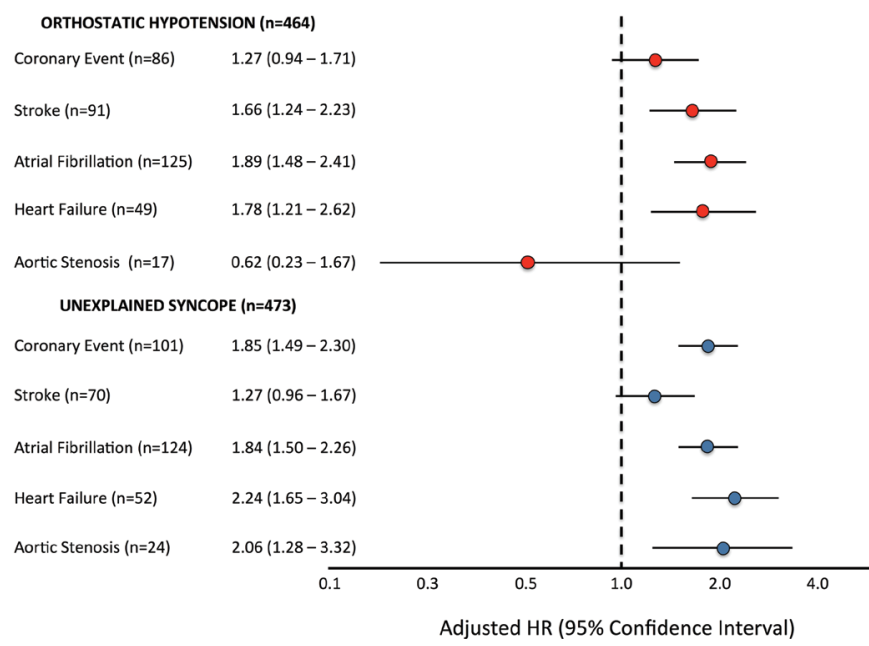

Figure 3 Risk estimation of incident cardiovascular (CV) events in Malmö Diet and Cancer Study cohort $(\mathrm{n}=29129)$ associated with history of orthostatic hypotension $(\mathrm{OH})$-related or unexplained syncope-related hospitalisation during follow-up. Multivariable-adjusted (age, sex, BMI, systolic $B P$, antihypertensive treatment, diabetes and current smoking) Cox regression model was applied by entering incident hospitalisation for $\mathrm{OH}$ or syncope prior to first-ever incident $\mathrm{CV}$ event (ie, coronary event, stroke, atrial fibrillation, heart failure and aortic valve stenosis) as an independent variable after exclusion of prevalent CV disease. Results are presented as adjusted $\mathrm{HRs}$ with $95 \% \mathrm{Cls}$. BMI, body mass index; BP, blood pressure.

two groups. While admissions for either syncope or $\mathrm{OH}$ predict all-cause mortality, heart failure and atrial fibrillation, diagnosis of syncope indicates higher risk of coronary events, aortic valve stenosis and $\mathrm{CV}$ death. In contrast, admission for $\mathrm{OH}$ indicates higher risk of stroke.

\section{Strengths and weaknesses of this study}

Our study has several strengths. First, we analysed the prognostic implications of hospital admissions attributed to unexplained syncope and $\mathrm{OH}$ in a population-based cohort of approximately 30000 middle-aged individuals without prevalent CV disease during a particularly long follow-up. Second, Swedish registers are subjected to annual quality control to ascertain completeness of information, and less than $1 \%$ of hospital admissions lack a proper discharge record with at least one principal diagnosis. ${ }^{12}$ Third, the validity of $\mathrm{CV}$ endpoints ascertained in our registers is high, indicating only a small impact of case misclassification bias.

Our study has some important limitations. Most patients with $\mathrm{OH}$ or syncope are not admitted to hospital for investigation and are either treated by general practitioners or fail to seek any medical advice. Our study material is therefore selected, and results may reflect a selection bias. Although the broad study from which these data were derived was designed as prospective, we conducted a database retrospective analysis, with its usual weaknesses. Furthermore, in the absence of a rescreening programme, we acknowledge the lack of important clinical information, such as blood pressure, changes in the antihypertensive drug regimen and electrocardiographic data at index event. Finally, in our study population, there was a predominance of women, and female sex was an inverse predictor of syncope (HR: $0.81,95 \%$ CI 0.66 to 0.98 ). It has been previously reported that female patients may be more prone to experience reflex syncope. ${ }^{13}$ Nonetheless, individuals deemed likely to have reflex syncope are usually evaluated as outpatients without hospitalisation. ${ }^{14}$ 


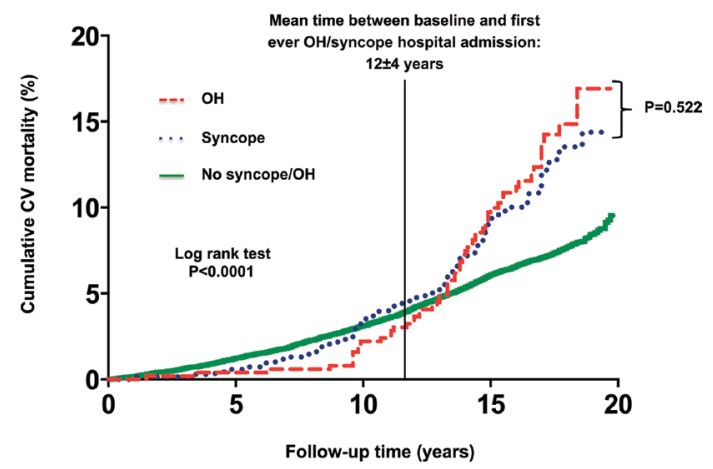

No. at risk

$\begin{array}{lccccc}\text { OH } & 464 & 458 & 450 & 324 & 0 \\ \text { Syncope } & 473 & 468 & 453 & 351 & 0 \\ \text { No syncope/OH } & 28192 & 27232 & 25742 & 20417 & 0\end{array}$

Figure 4 Long-term cumulative incidence of cardiovascular (CV) mortality rates according to incident syncope-related and $\mathrm{OH}$-related hospital admission ( $n=29129$ ). Kaplan-Meier curves with regard to CV mortality stratified according to incident syncope-related (blue) and $\mathrm{OH}$-related (red) hospital admission: inpatients showed a significantly lower survival rate (Log-rank test $p<0.001)$ compared with those never hospitalised for syncope or $\mathrm{OH}$ (green). The black vertical line at 12 years is a landmark point indicating mean time between baseline and first-ever $\mathrm{OH} /$ syncope hospital admission. Thereafter, survival curves for $\mathrm{OH} /$ syncope-related hospital admission and non-hospitalised patients begin and continue to diverge. $\mathrm{OH}$, orthostatic hypotension.

\section{Strengths and weaknesses in relation to other studies}

The average rate of hospital admissions for syncope was 1.2 per 1000 person-years, which is consistent with the epidemiological data reporting between one and two syncope-related admissions per 1000 person-years in the general population. Patients referred to hospitals constitute only a minority $(\approx 10 \%)$ of those who seek medical assistance due to unexplained loss of consciousness. They are usually older and present with features of high-risk syncope that require rapid evaluation. ${ }^{3}$ Interestingly, admission rate for $\mathrm{OH}$ was very similar.

The estimated prevalence of $\mathrm{OH}$ in adults older than 55 years may be extrapolated from previous studies and is approximately $5 \%-15 \% .{ }^{10} 15$ If applied to our study population, it would mean that about one in eight patients with $\mathrm{OH}$ had been admitted at least once for this condition during follow-up. Admitted patients with $\mathrm{OH}$ were most likely more symptomatic: previous studies suggest that majority of patients with $\mathrm{OH}$ are unaware of their problem. ${ }^{16}$ Apart from age, we identified prevalent CV disease, hypertension, antihypertensive treatment and use of diuretics in particular, as predictors of syncope hospitalisations, in line with recent SPRINT study, where a more intensive treatment arm was associated with higher risk of syncope. ${ }^{17}$

A history of $\mathrm{CV}$ disease was also predictive of admission for syncope; a possible explanation is that syncope may have revealed an undetected $\mathrm{CV}$ condition, such as paroxysmal cardiac arrhythmia, or that prevalent CV disease predisposed to circulatory collapse by its negative impact on the heart and vessels, for example, via postinfarction cardiomyopathy, valvular heart disease or atrial fibrillation. Unexpectedly, antihypertensive treatment and prevalent $\mathrm{CV}$ disease had no impact on OH-related admissions, also in line with the results of SPRINT. ${ }^{17}$ This is at variance from the common belief that use of antihypertensive drugs is a major cause of $\mathrm{OH} .{ }^{4}$ In contrast, diabetes was predictive of $\mathrm{OH}$-related admissions, as is generally accepted. ${ }^{18}$

There is no consensus whether discharge diagnoses of syncope/ $\mathrm{OH}$ without specific concurrent $\mathrm{CV}$ disease should be seen as warning of future CV complications. A report from Framingham showed no increased risk of adverse CV outcomes among patients with vasovagal and orthostatic syncope. ${ }^{19}$ However, one-third of syncope aetiology was not defined, and this subgroup demonstrated both higher mortality and CV morbidity. A more recent study suggested hospitalisation for non-cardiac syncope in 'healthy' individuals might predict death, stroke, CV hospitalisation, device implantation and recurrent syncope. ${ }^{2}$ Furthermore, among patients presenting syncope at emergency department, the probability of adverse outcome within 2 years is approximately $25 \%$, higher than in general population. ${ }^{20}$ However, it cannot be excluded that a serious episode of syncope, even if not associated with detectable $\mathrm{CV}$ disorder during hospitalisation, may lead to postdischarge diagnostic vigilance and higher rate of CV disease detection.

Regarding $\mathrm{OH}$, studies exploring long-term prognosis associated with hospital admissions for $\mathrm{OH}$ are very sparse. In large population-based cohorts, prevalent $\mathrm{OH}$ has been consistently linked with increased mortality and risk of CV events. ${ }^{121-23}$ However, the occurrence of hospital admissions due to worsening $\mathrm{OH}$, typically syncope and/or unexplained fall trauma, has not been previously reported.

It has been reported that $30 \%-50 \%$ of patients with syncope leave hospital without a clear explanation of cause. ${ }^{14} 24$ Older patients admitted due to the event interpreted as unexplained syncope may have had an undetected CV condition, such as paroxysmal cardiac arrhythmia with or without underlying structural heart disease. These results emphasise the role of implantable cardiac monitors in the postdischarge work-up of older patients with unexplained syncope, as proposed by Syncope Unit Project investigators. ${ }^{25}$ Moreover, a recent study of patients admitted for a first episode of syncope demonstrated that one in six cases showed evidence of pulmonary embolism as the likely syncope aetiology, ${ }^{26}$ rarely considered as a possible diagnosis. It should be also remembered that the presence of vasovagal syncope in a patient's history might be a marker of susceptibility to a coronary event. We have previously reported that history of vasovagal syncope indicates higher likelihood of prevalent myocardial infarction in middle-aged adults. ${ }^{27}$

As expected, patients discharged with a final diagnosis of $\mathrm{OH}$ demonstrated increased incidence of $\mathrm{CV}$ disease. These patients

Table 3 Risk estimation of cardiovascular (CV) death and all-cause death associated with history of orthostatic hypotension-related or unexplained syncope-related hospitalisation during follow-up in the Malmö Diet and Cancer Study cohort ( $\mathrm{n}=29129)$ individuals without prevalent CV disease)

\begin{tabular}{|c|c|c|c|c|c|c|}
\hline \multirow[b]{2}{*}{ Hospital admission } & \multicolumn{3}{|l|}{ CV death } & \multicolumn{3}{|c|}{ All-cause death } \\
\hline & Event (n) & aHR $(95 \% \mathrm{Cl})$ & $\mathrm{p}$ Value & Event (n) & aHR $(95 \% \mathrm{Cl})$ & $\mathrm{p}$ Value \\
\hline $\begin{array}{l}\text { Unexplained syncope } \\
(\mathrm{n}=473)\end{array}$ & 52 & 1.72 (1.23 to 2.42$)$ & 0.002 & 138 & 1.22 (1.09 to 1.37$)$ & 0.001 \\
\hline $\mathrm{OH}(\mathrm{n}=464)$ & 47 & 1.33 (0.93 to 1.92$)$ & 0.124 & 121 & 1.14 (1.01 to 1.30$)$ & 0.034 \\
\hline
\end{tabular}

Model adjusted for age, sex, current smoking, body mass index, diabetes, systolic blood pressure, use of hypolipidaemic agents and antihypertensive treatment.

aHR, adjusted $\mathrm{HR} ; \mathrm{OH}$, orthostatic hypotension. 
had confirmed, and symptomatic $\mathrm{OH}$ and should share the same prospective risks as the whole $\mathrm{OH}$ population. However, hospital admission due to $\mathrm{OH}$ might be seen as a marker of general frailty, comorbidities and higher $\mathrm{CV}$ risk compared with asymptomatic $\mathrm{OH}$. We have previously reported that patients with syncope triggered by $\mathrm{OH}$ show unfavourable neuroendocrine and procoagulatory changes ${ }^{2829}$ and that $\mathrm{OH}$ is associated with structural cardiac changes. ${ }^{30}$ Thus, patients with symptomatic $\mathrm{OH}$ constitute a vulnerable group in excess of the age-matched population in susceptibility to CV disease, in parallel with high-risk conditions such as hypertension and diabetes.

\section{Meaning of the study}

Our study fills an important gap in knowledge suggesting syncope-related and $\mathrm{OH}$-related admissions, without concomitant $\mathrm{CV}$ disease, previously seen as benign events, indeed herald higher risk of more serious $\mathrm{CV}$ events.

Furthermore, we underline the need for precise classification of syncope aetiology after admission to hospital as prognostic implications of unexplained syncope-related event and $\mathrm{OH}$, although partially overlapping, differ in regard to type of CV event.

\section{CONCLUSIONS}

Hospital admissions for syncope and $\mathrm{OH}$ in middle-aged adults increase with advancing age and are associated with common comorbidities, diabetes and hypertension. Admission for syncope and $\mathrm{OH}$ predicts development of heart failure and atrial fibrillation. Moreover, admission for syncope indicates higher risk of coronary events and aortic valve stenosis, whereas admission for $\mathrm{OH}$ predicts stroke. Patients admitted for unexplained syncope have higher risk of both all-cause and CV death, whereas those admitted for $\mathrm{OH}$ demonstrate higher all-cause mortality.

Contributors EY: conception and study design, interpretation of data, manuscript drafting and approval of the version of the manuscript to be published. FR: statistical analysis and interpretation of data, manuscript drafting, critical revision of the article and approval of the version of the manuscript to be published. MM: conception and study design, manuscript drafting, critical revision of the article and approval of the version of the manuscript to be published. RS: conception and study design, manuscript drafting, critical revision of the article and approval of the version of the manuscript to be published. SG: interpretation of data, critical revision of the article and approval of the version of the manuscript to be published. RDC: interpretation of data, critical revision of the article and approval of the version of the manuscript to be published. OM: data collection, critical revision of the article and approval of the version of the manuscript to be published. AF: conception and study design, data

\section{Key messages}

What is already known on this subject?

There is no evidence-based consensus about prognostic significance of hospital admission related to unexplained syncope and orthostatic hypotension $(\mathrm{OH})$.

\section{What might this study add?}

Hospital admissions for unexplained syncope and $\mathrm{OH}$, previously seen as benign events, herald higher risk of cardiovascular morbidity and all-cause mortality and convey independent prognostic information. Hospital admission for unexplained syncope indicates higher risk of coronary events (HR: 1.85 , $95 \% \mathrm{Cl} 1.49$ to 2.30 ) and cardiovascular death (HR: $1.72,95 \% \mathrm{Cl}$ 1.23 to 2.42 ), whereas admission for $\mathrm{OH}$ significantly predicts stroke (HR: $1.66,95 \% \mathrm{Cl} 1.24$ to 2.23 ).

\section{How might this impact on clinical practice?}

Hospital admissions for unexplained syncope and $\mathrm{OH}$ should be regarded as a warning sign of future cardiovascular events. collection, statistical analysis and interpretation of data, critical revision of the article and approval of the version of the manuscript to be published.

Funding This work was supported by grants from the Swedish Medical Research Council, the Swedish Heart and Lung Foundation, the Medical Faculty of Lund University, Malmö University Hospital, the Albert Påhlsson Research Foundation, the Crafoord Foundation, the Ernhold Lundströms Research Foundation, the Region Skane, the Hulda and Conrad Mossfelt Foundation, the King Gustaf V and Queen Victoria Foundation, The Wallenberg Foundation and the Lennart Hanssons Memorial Fund.

Competing interests All authors have completed the ICMJE uniform disclosure at www.icmje.org/coi_disclosure.pdf and declare: AF reports personal fees from Cardiome Corp. and a patent Thermo Fisher pending outside the submitted work; RDC reports grants from Boehringer-Ingelheim, Bayer and BMS/Pfizer, personal fees from Boehringer-Ingelheim, Bayer, BMS/Pfizer, Daiichi-Sankyo and Lilly outside the submitted work; RS reports personal fees and other from Medtronic Inc., St. Jude Medical Inc. outside the submitted work; RS performs consultancy for Medtronic Inc.; RS is a member of the speaker's Bureau St. Jude Medical/Abbott Inc.; RS is shareholder in Boston Scientific Inc., Edwards Lifesciences Inc., Shire PLC, Roche SA and Astrazeneca PLC; no other relationships or activities that could appear to have influenced the submitted work.

Ethics approval Regional Ethical Review Board in Lund, Sweden.

Provenance and peer review Not commissioned; externally peer reviewed.

Open Access This is an Open Access article distributed in accordance with the Creative Commons Attribution Non Commercial (CC BY-NC 4.0) license, which permits others to distribute, remix, adapt, build upon this work non-commercially, and license their derivative works on different terms, provided the original work is properly cited and the use is non-commercial. See: http://creativecommons.org/licenses/by-nc/4.0/

(c) Article author(s) (or their employer(s) unless otherwise stated in the text of the article) 2018. All rights reserved. No commercial use is permitted unless otherwise expressly granted.

\section{REFERENCES}

1 Ricci F, Fedorowski A, Radico F, et al. Cardiovascular morbidity and mortality related to orthostatic hypotension: a meta-analysis of prospective observational studies. Eur Heart J 2015;36:1609-17.

2 Ruwald MH, Hansen ML, Lamberts $M$, et al. Prognosis among healthy individuals discharged with a primary diagnosis of syncope. J Am Coll Cardiol 2013;61:325-32

3 Moya A, Sutton R, Ammirati F, et al. Guidelines for the diagnosis and management of Syncope (version 2009): the Task Force for the diagnosis and management of Syncope of the European Society of Cardiology (ESC). Eur Heart J 2009;30:2631-71.

4 Ricci F, De Caterina R, Fedorowski A, et al. Prognosis, and treatment. J Am Coll Cardiol 2015;66:848-60.

5 Ruwald MH, Hansen ML, Lamberts M, et al. Accuracy of the ICD-10 discharge diagnosis for Syncope. Europace 2013;15:595-600.

6 Berglund G, Elmstähl S, Janzon L, et al. The Malmo Diet and Cancer study. design and feasibility. J Intern Med 1993;233:45-51.

7 Smith JG, Platonov PG, Hedblad B, et al. Atrial fibrillation in the Malmö Diet and Cancer study: a study of occurrence, risk factors and diagnostic validity. Eur J Epidemiol 2010;25:95-102.

8 Mancia G, De Backer G, Dominiczak A, et al. 2007 guidelines for the management of arterial hypertension: the Task Force for the management of arterial hypertension of the european Society of hypertension (ESH) and of the european Society of Cardiology (ESC). J Hypertens 20072007;25:1105-87;25:1105-87.

9 Freeman R, Wieling W, Axelrod FB, et al. Consensus statement on the definition of orthostatic hypotension, neurally mediated Syncope and the postural tachycardia syndrome. Clin Auton Res 2011;21:69-72.

10 Fedorowski A, Stavenow L, Hedblad B, et al. Orthostatic hypotension predicts all-cause mortality and coronary events in middle-aged individuals (The Malmo Preventive Project). Eur Heart J 2010;31:85-91.

11 Ingelsson E, Arnlöv J, Sundström J, et al. The validity of a diagnosis of heart failure in a hospital discharge register. Eur J Heart Fail 2005;7:787-91.

12 Friberg L, Benson L, Rosenqvist M, et al. Assessment of female sex as a risk factor in atrial fibrillation in Sweden: nationwide retrospective cohort study. BMJ 2012;344:e3522.

13 Kenny RA, Bhangu J, King-Kallimanis BL. Epidemiology of Syncope/collapse in younger and older western patient populations. Prog Cardiovasc Dis 2013;55:357-63.

14 Syncope KWNN Engl J Med 2000;343:1856-62.

15 Rose KM, Eigenbrodt ML, Biga RL, et al. Orthostatic hypotension predicts mortality in middle-aged adults: the Atherosclerosis Risk In Communities (ARIC) Study. Circulation 2006;114:630-6.

16 Rutan GH, Hermanson B, Bild DE, et al. Orthostatic hypotension in older adults. the Cardiovascular Health Study. CHS Collaborative Research Group. Hypertension 1992; 19(6 Pt 1):508-19.

17 Wright JT, Williamson JD, Whelton PK, et al. A randomized trial of intensive versus standard Blood-Pressure control. N Engl J Med 2015;373:2103-16. 
18 Goldstein DS, Sharabi Y. Neurogenic orthostatic hypotension: a pathophysiological approach. Circulation 2009;119:139-46.

19 Soteriades ES, Evans JC, Larson MG, et al. Incidence and prognosis of Syncope. N Engl J Med 2002;347:878-85.

20 Solbiati M, Casazza G, Dipaola F, et al. Syncope recurrence and mortality: a systematic review. Europace 2015;17:300-8.

21 Rose KM, Tyroler HA, Nardo CJ, et al. Orthostatic hypotension and the incidence of coronary heart disease: the Atherosclerosis risk in communities study. Am J Hypertens 2000;13(6 Pt 1):571-8

22 Yatsuya $\mathrm{H}$, Folsom AR, Alonso A, et al. Postural changes in blood pressure and incidence of ischemic stroke subtypes: the ARIC study. Hypertension 2011;57:167-73.

23 Angelousi A, Girerd N, Benetos A, et al. Association between orthostatic hypotension and cardiovascular risk, cerebrovascular risk, cognitive decline and falls as well as overall mortality: a systematic review and meta-analysis. J Hypertens 2014;32:1562-71.
24 Grossman SA, Shapiro NI, Van Epp S, et al. Sex differences in the emergency department evaluation of elderly patients with Syncope. J Gerontol A Biol Sci Med Sci 2005;60:1202-5.

25 Brignole M, Ammirati F, Arabia F, et al. Assessment of a standardized algorithm for cardiac pacing in older patients affected by severe unpredictable reflex syncopes. Eur Heart J 2015:36:1529-35.

26 Prandoni P, Lensing AW, Prins $\mathrm{MH}$, et al. Prevalence of pulmonary embolism among patients hospitalized for Syncope. N Engl J Med 2016;375:1524-31.

27 Zysko D, Melander O, Fedorowski A. Vasovagal Syncope related to emotional stress predicts coronary events in later life. Pacing Clin Electrophysiol 2013;36:1000-6.

28 Nilsson D, Sutton R, Tas W, et al. Orthostatic changes in hemodynamics and Cardiovascular biomarkers in dysautonomic patients. PLoS One 2015;10:e0128962.

29 Isma N, Sutton R, Hillarp A, et al. Higher levels of Von Willebrand factor in patients with Syncope due to orthostatic hypotension. J Hypertens 2015;33:1594-601.

30 Magnusson M, Holm H, Bachus E, et al. Orthostatic Hypotension and cardiac changes after Long-Term Follow-Up. Am J Hypertens 2016;29:847-52. 